\title{
MANAGEMENT OF ON-LINE SALES CHANNELS AT HOTELS: CHANNEL MANAGER SYSTEM
}

\author{
Ali Avan ${ }^{1}$ \\ Ahmet Baytok ${ }^{2}$ \\ Özcan Zorlu ${ }^{3}$ \\ Murat Toker ${ }^{4}$
}

\begin{abstract}
Rapid development of technology has caused a dramatic change at marketing and purchase types of products in the last 20 years. This change which is also characterized by the growing rates of internet usage and online sales has affected hotel enterprises like all other business. Especially, intensive usage and accessibility of internet has established a dynamic web based platform where the hotel enterprises can easily market their services in which the consumers can access those services quickly, easily and cheaply. These web-based platforms named as on-line sales channels (OSCs) show an upward trend as an alternative to traditional marketing. However, today OSCs have become comparable for both end-users and channel managers as a result of the growing number of such platforms. And this fact has made the knowledge standardization obligatory in terms of marketing ethics, marketing style and on-line sales agreement. At this point, Channel Manager System (CMS) has become as a way of knowledge standardization for the hotel enterprises. Usage of CMS has made the management of relevant processes easier by enabling fast $\&$ easy update of necessary information, pictures, daily activities and prices in hotels. Within this context, this study examines contributions and amenities of CMS in terms of OSCs with an application which is currently used in a thermal hotel.
\end{abstract}

Key words: On-line sales channels, on-line marketing, Channel Manager System.

\section{INTRODUCTION}

Recent developments in information technologies, reaching and using information easily, and rapid developments in interactive communication turned the world into a global village and necessitated to make a new definition of goods and services production and other business activities. This process is accelerated by the developments in personal computer, laptop and smart phone technologies, by the increase interest and use of such technologies by individuals (Murphy, Chen and Cossutta, 2016: 44) and with the support of internet and web applications (Aksu and Tarcan, 2002: 94).According to Internetworldstats' internet usage statistics, the number of internet users in the world reached to 3.079.339.857. The number of tablet owners is 1,06 billion and 1,91 billion people are smart phone users.Moreover the number of internet users and the machines providing internet access is increasing constantly. The number of internet users increased $753 \%$ in the last 15 years.It is estimated that the number of smart phone users will reach to 2,56 billion people by 2018 (World Internet Users and 2015 Population Stats; Smartphone Users Worldwide 2012-2018).

Tourism is one of the fields in which information technologies are frequently used today. The basic characteristics of tourism -inseparability, perishability and intangibilityforce tourist to gain more information before making their travel purchase decisions.For

\footnotetext{
${ }^{1}$ Res. Assist. Dr., Afyon Kocatepe University, Faculty of Tourism, Afyonkarahisar, Turkey.

${ }^{2}$ Assoc. Prof. Dr.,Afyon Kocatepe University, Faculty of Tourism, Afyonkarahisar, Turkey.

${ }^{3}$ Assist. Prof. Dr.Afyon Kocatepe University, Faculty of Tourism, Afyonkarahisar, Turkey.

${ }^{4}$ Specialist, Ikbal Thermal Deluxe Hotel, Afyonkarahisar, Turkey.
} 
this reason, internet is the most important information source for travel planning and hotel reservations (Murphy, Chen and Cossutta, 2016: 45; Kucukusta et al., 2015: 185). While enterprises in tourism sector use information technologies in the marketing and sales stages of their products, the tourists who benefit from the utilities of these enterprises use information technologies before making their purchase decisions (Heung, 2003: 370).Fesenmaier et al., (2011) define the websites used for travel planning as "general search engines", "suppliers' sites", "online travel agencies", "friends and family review sites", "destination sites", "general travel sites", "travel search engines", "travel guidebook sites", "community sites", "newspaper/magazines sites", "consumer content generates sites" and "social networking sites" (cited in Murphy, Dang and Chen, 2015: 765).But the existence of numerous online distribution channels related to tourism sector formed by parties independent from each other require consumers to spend more time in order to gain up-to-date and reliable information (especially for making price comparisons) (Law, Chan and Goh, 2007: 496). Also, some problems arising from the emergence of different information sources cause disruptions in the activities of businesses in the field, problems related to ethics and a damage to image of the businesses.For this reason, it is imperative to develop applications for the use of both businesses and tourists which will enable effective use of internet and web page.

Within this context, the aim of the study is to present the convenience and benefits of channel manager system through the booking and registration processes both for tourists and hotel enterprises with an example at a thermal hotel.

\section{LITERATURE REVIEW}

The main factors which influence the success of hotels in the 21 st century are globalization, technological development, changes in consumer choices, differentiation in the competition of hotels, horizontal and vertical combination, and legal regulations (Aksu and Tarcan, 2002: 94). In relation to technological developments which are considered among the success factors of hotels, the use of information technologies has become a global market where vendors and purchasers meet in order to share information for the purpose of introduction and sale of travel related goods and services (Law, Chan and Goh, 2007: 495). The choice of the most efficient distribution channel for a product is at the same time the determiner of the power and status of that product in the market (Kucukusta et al. 2015: 185).In this regard, information technologies have particularly changed the distribution channels of hotel enterprises. Traditionally, hotel enterprises realize the sales of their products through intermediaries which are tour operators and travel agencies. The growth of internet with the development of technologybrought out the emergence of online travel distribution channels and a revolutionary transformation in the realization of travel records (Law, Chan and Goh, 2007: 495).

Online sales channels offer opportunities to hotels to advertise their products directly and to reach their guests without the borders of time and geographic location in a broader market with lower distribution costs (Kucukusta et al. 2015: 186).Increasing the sales, diversifying goods and services, rapid response to changes in market conditions, increasing service quality, increasing efficiency, and finding, collecting, evaluating information and feedback can be counted among the benefits of information technologies for hotels (Aksu and Tarcan, 2002: 94-95). For this reason, hotels adopt the use of electronic commerce (eb2c) more day by day and create web pages in order to inform consumers about their products, and to advertise and market their goods and services. The main use of web sites 
by hotels is to present general information about their facilities and to provide communication opportunities. The main feature of web sites is to function as an advertisement brochure.In addition to this, online registration and reservation is the other most important feature which is expected to be on hotel web sites (Zafiropoulas, Vrana and Paschaloudis, 2006: 156-161).

Web sites of hotels are an important source of information and a tool of competitive marketing.For this reason, businesses should renew their web sites frequently and make it attractive for new customers.From consumers perspective, usefulness of a web site is as important as its ease of use.In terms of usefulness, expectations of users from web sites are speed, efficiency, easiness and providing information.For this reason, planners of web sites of hotels should take usefulness as much as ease of use in to consideration while creating web sites.The fusion of these features become a describingfactor for their online registration intentions.Another important issue which should be taken into consideration is the benefits of online registration.For example, in a study made in Hong Kong, it is found out that users approach online sales channels with a benefit oriented view (Kucukusta et al. 2015: 195).Another issue which should be addressed by hotel web site planners is the defining role of online social networks and their influence on consumers' choice of destinations and businesses.In their study on consumers' sharing information on travel oriented online social networks, Bilgihan et al. (2016) found out that consumers rely on information about choosing places for travelling and take the advices on online social networks before making their decisions.Accordingly, it is stated in the study that placing applications that will facilitate information exchange of consumers will provide benefits for hotel enterprises.Another issue brought into discussion by the researchers is the importance of adding an icon to business web site which will ensure reaching to online social networks.

An individual's search on the internet about hospitality industry takes place before deciding where to go for holiday.Internet users' web searches for accommodation purposes have increased $26 \%$ in 2014 compared to 2013. Internet usage rates for business oriented travel is $69 \%$ and for leisure purposes is $65 \%$.According to realized holiday rates, $60 \%$ of users made their first search on internet (Google Travel Study, June 2014). These figures and the realized accommodation statistics of internet use rates direct hotels towards new marketing channels, namely Online Sales Channels. These channels are virtual markets where hotels can offer their services and products, put them on the market and take reservations, and get payments for these reservations.Contrary to classic travel agencies which have an established order, online sales channels offer many benefits to hotel since they do not require more procedures, offer instant control of price, quota and content, and because of their flexible use feature.For the hotels which consider guest satisfaction as the primary goal and adopt online sales as virtual businesses, the most important factors which influence online sales and the income yielding from these channels are the presentation and price of the product. For this reason, in order to increase marketing and sales of their products, hotels have to develop marketing strategies which are planned beforehand and include online channels. Because the price and quotas can be seen not only by potential guests named as end users but also by competing hotels and other regional travel agencies. This situation necessitates using channel management systems which are useful for keeping the website up-to-date, protecting its competitiveness and managing it effectively.Businesses working with channel management systems obtain some advantages and facilities at online marketing and sales preferences of consumers. 


\section{ONLINE SALES CHANNELS}

As a result of the development of information technologies, intense effects of internet usage in every field of social and business life caused to the definition of the $21^{\text {st }}$ century characterized with the virtual concepts such as e-life and online buying. Both in business and social life, the increase of virtual activities and events day by day also bring important changes to the buying behaviors of individuals. Traditional buying activities in which customers realize their purchases through seeing, tasting or experiencing continued until 2000s and left its place to online buying behavior gradually nowadays.Thus, as mentioned before, internet usage and smart phone/tablet usage rates showa regular increase throughout the world every year, and accordingly the levels of online buying increase regularly.

The continuation and steady increase of online buying activities caused radical changes in the traditional functioning of tourism sector which is located in service industryas in all sectors. Although there is a wide conviction that purchasing activities in tourism generally occur through tour operators and travel agencies, upon request or through pre-experience, the increase in travel search engines where holiday opportunities are displayed and detailed information about touristic activities brought different perspectives to this traditional view.One of the most important effects of social media and internet usage on touristic purchasing behaviors is the increase in the popularity of meta-search sites/engines whose numbers increased rapidly recently.Opening the use of meta-search engines to potential guests caused a differentiation in the buying process both for hotels and the guests.In its study named "The 2014 Traveler's Road to Decision" conducted with 5000 people who travel at least once individually or three times for business, Google identified that $74 \%$ of 3500 participants of leisure travelers use online search for travel planning.It is found out that meta-search engines is the most popular method among online searches with $60 \%$ and individuals pass from these search engines to purchase/reservation process in between 1218 seconds (Google Travel Study, June 2014).

With the introduction of meta-search engines into the daily lives, individuals who want to have holidays changed their purchase behaviors from traditional buying methods to searching hotels directly on internet from the region, destination or directly with the name of the hotel in order to find the most suitable options for them.At this stage, sensibility of a great majority of individuals to prices and quality results in numerous comparisons on virtual environment.Quality-price comparisons of planned holidays are basically done through meta-search engines.Individuals who reach advisory information about the holiday experience through popular search engines mainly such as Trivago, Tripadvisor, KAYAK, Travelocity, Priceline, Orbitz can also see many online sales channels at the same time.

Online sales channels which can be described as virtual markets where hotel enterprises put their products and services on the market, take reservations and/or sale them are displayed on a single screen by meta-search engines. The individual who wants to experience a holiday can see different price options and special promotions about the hotel he/she wants stay instantly, can make a reservation and/or do the purchase transaction directly without using any kind of intermediaries. Online sales channels, reaching up to hundreds, are a new market for hotels; they do not require a lot of procedures and are flexible virtual businesses because the control of price, content and quota are in the hand of the business. Moreover, the elimination of many procedures in traditional buying process for potential tourists and time saving features direct hotels to more effective use of such channels.New channels are added to this system every day and among them Booking.com, 
Expedia, HRS and Hotelbeds can be named as the most popular ones. They make up an interactive marketplace both for potential tourists and businesses with many different features.It is possible to explain this process taking place between the individual's buying behavior and hotels' marketing-sales strategies which causes radical changes with a model given below.

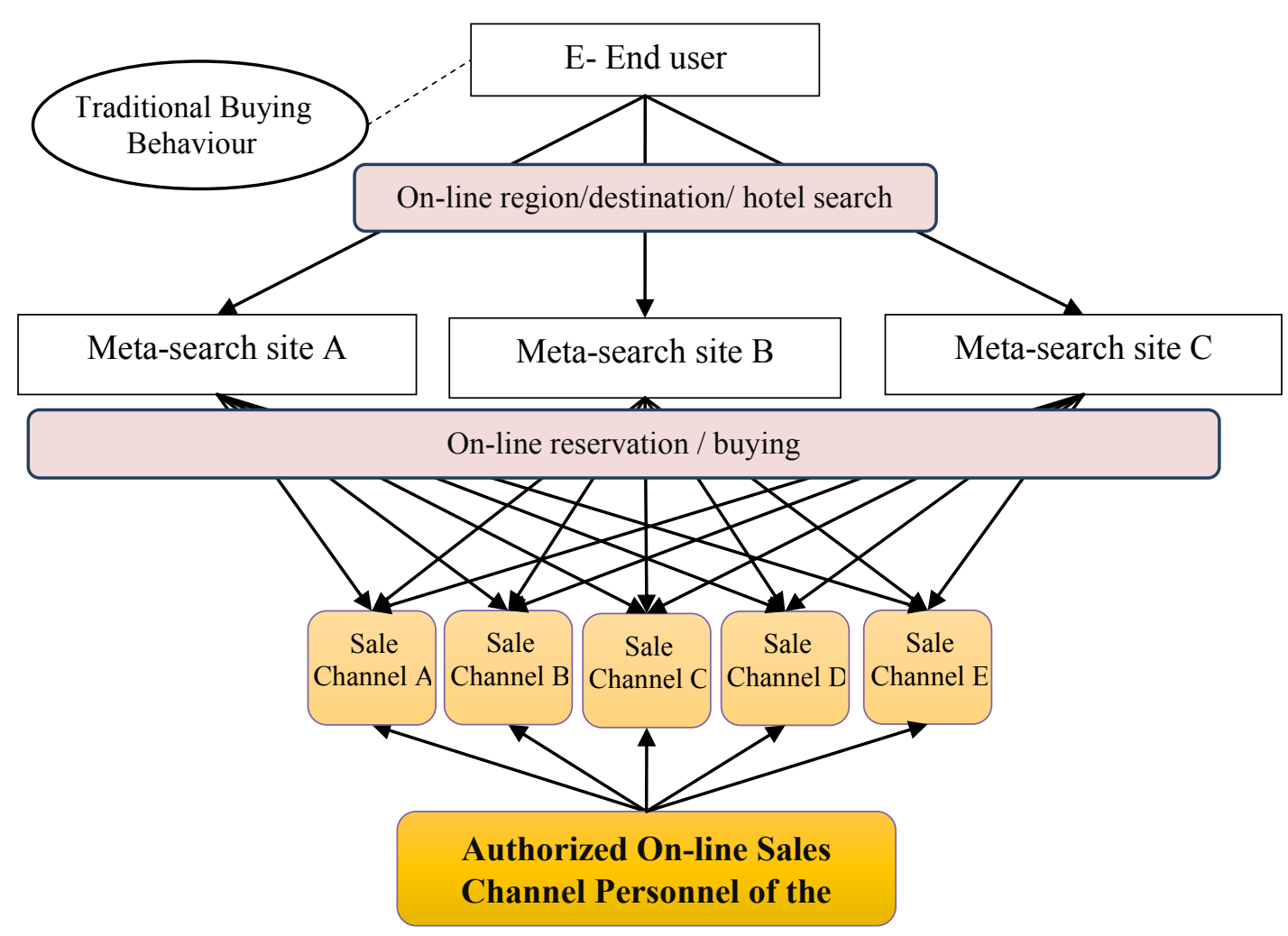

Fig. 1: On-line buying behavior of tourism products via e-sales channels

This model is important since it includes the online buying behavior of individuals through meta-search engines and explains how hotels get into this process.Before introducing their services into this interactive market, hotels have to input their all the information into the sales channel according to their marketing strategies. Sales channels give place to the number of hotel's stars, location, room types and features, accommodation options changing depending on price, accommodation information, room quota status, hotel rooms and service units, visuals of general locations of the hotel and guest comments.In order to compete in the interactive market, hotels should first upload all the information to the related channels except guest comments and thus make up a product range by making product/service definitions.Moreover, in order to provide a competitive advantage in the interactive market, hotels should always be one step ahead of their rivals, increase their visibility on the channel and realize instant price changes.At this stage, it is impossible for the personnel who is responsible for controlling online sales to keep numerous sales channels active and up-to-date all the time, change price levels instantly, follow room reservations and/or sales immediately. 


\section{MANAGEMENT OF ONLINE SALES CHANNELS AND CHANNEL MANAGER SYSTEM}

With the increase in touristic purchases from online sales channels and with the increase in the number of sales channels, hotels had to appear more on sales channels and keep their information actual all the time in order to exist in the interactive marketplace.In addition to this, while updating sales channels, price and quota of the hotel is required to be defined by taking the current status of the hotel and the defined price-quota information should be reflected on all the sales channels simultaneously.Furthermore, it is imperative to inform local agencies about these updates made on online sales channels at the same time and revenue losses resulting from the dilemma of wrong price and quota, and/or overbooking should be prevented. Nowadays, hotels make up units responsible for online marketing in order to prevent such losses and wrong operations. The existence of numerous sales channels makes the use of channel manager systems (CMS) necessary which bring such channels together.CMS, with a simple definition, is a system which combines many online sales channels on a single control panel and thus enables the simultaneous control and synchronization of these channels.These kind of systems enhance the command and control of hotel on sales channels during the online buying process. This process can be shown as in Figure 2.

As can be seen from Figure 2, the most significant function of CMS is its ability to maintain online sales channels of hotels rapidly.For this purpose, hotel managements make agreements with one of the national or international CMSs in accordance to their sales and marketing strategies.Functional magnitude of the preferred CMS directly influences the sales and income amounts which will be obtained from the interactive market. While with small scaled and not very functional CMSs, hotels can only control and update the system, especially with international scoped CMSs. CMS executives may also increase the number of the channels in which hotelsmonitored and in response hotels may have the power to decrease the commission rates.Following the deal with any one of the CMSs, hotel representatives are given authorization by CMS and thus they can input hotel information and visuals to the system only once. Since the responsible person of the hotel can connect to all the online sales channels on the system automatically, the input content and visual are screened to all the onlinesales channels in seconds.

After screening the content and visuals of the hotel on the channels, the quotas and prices defined by the hotel are uploaded to system with bar rate through a control panel.At this stage, by defining bar rate, hotels can prevent out any sales which are under the bar rate.During this process, hotel can make an update on all the sales channels or on a single channel through CMS.On the other hand, the multitude of online sales channels on CMS system and/or its increase in time can ease hotel in terms of finding new markets. While hotel reach new markets through CMS, representatives of CMS make the necessary connections and deals with the sales channels in question and invoicing.In relation to the various number of channels on CMS system, being screened on many channels and being on upper ranks during screening give hotel businesses a chance to decrease commission rates made to these kind of channels. At this stage, the request for a commission depending on the sales quotas on online sales channels by the CMS authorities by relying on their international power and agreements results in payments of lower commission rate amounts by hotel businesses. Thus, hotel may both find new markets and make savings in terms of time and cost of commission payments. 


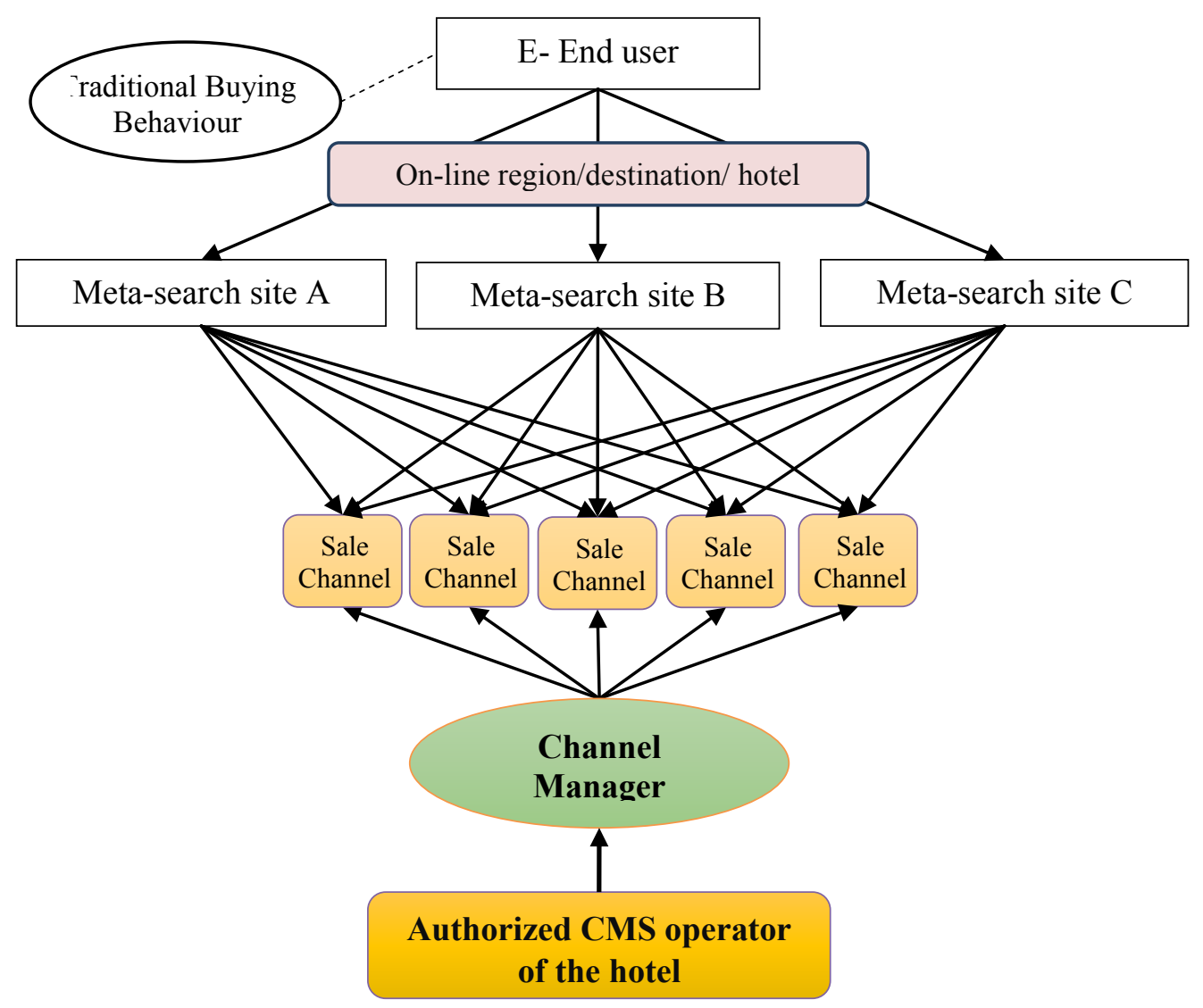

Fig. 2: Channel Manager System at On-line Buying Behaviour

Another important contribution of CMS is its feature to provide regular information about the competitors in the region.CMS authorities analyze the region where the hotel operates, weekly, monthly and seasonally, and provide detailed reports for the occupancy rates and prices about the other hotels in the region.Thus, the hotels can follow the region without showing any effort and accordingly, they can develop proactive marketing strategies in short time.Information given by CMS authorities about the near future events which may come up in the region enhances the success of proactive marketing strategies and its efficiency.In this process, while CMS develop strategies and applications in order to increase its sales amounts, it also contributes to the sales of the hotels and it boosts the visibility of the hotel on meta-search engines.

Another advantage of CMS for hotel enterprises is its convenience for reservations and invoicing.In situations where hotels do not use CMS, they accept reservations through numerous online sales channels and have to update their room quotas instantly according to accepted reservations.Management of reservations become much more difficult when individual reservations (by phone, mail or individually)added to online ones. Moreover, hotels have to do invoicing and collecting for all these reservations separately.In situations where CMS is used, hotels accept all the reservations through a single control panel and have an opportunity to control reservations from one single point.In connection to reservation management, CMSs make a significant contribution to hotels in terms of room 
sales revenues.Instant control of all sales channels through CMS enable the hotel management to offer remaining rooms with a higher price when the number of vacant rooms decrease.By this way, hotel management can increase its profitability when the occupancy rate goes up.

CMSs also help hotels with the payments. It decreases both room price collection process time and commissions paid for collection. When reservations are made through phone, mail or individually, prices are generally collected when the stay is realized and nearly $4 \%$ commission is paid forpayments made with credit cards.But with reservations made through CMS, the price is collected in advance and transferred to hotels account during the daytime.By this way, hotels can take guaranteed reservations and do in advance price collection.Also paying a maximum commission of 3\% to CMS according to the content of the agreements made, hotels can gain an advantage with the commissions.Generally hotel businesses pay commission for CMS use according to the number of reservations taken.In some cases, they rent CMS use yearly.

While CMSs have numerous advantages for online sales and sales channels, hotels should take some precautions in order to get optimum benefit from such systems; a) they should create their online sales strategies, b) employ qualified personnel in order to operate the system efficiently and c) the system should be followed and updated 24 hours a day.In situations where prerequisites are met and correct strategies are applied, CMS usage prevents unnecessary workload of sales-marketing and reservations, and thus the number of personnel assigned for these duties can be reduced and work processes can be facilitated. As a result, it can be said that CMS is an important sales-reservation management tool in today's world where online purchases are important for hotel businesses.

\section{CONCLUSION}

Online sales for touristic purposes haveincreased steadily in the last decade.Accordingly, using online sales channels become an important alternative for the end users (tourists) during their purchase decisions.Besides, online sales channels facilitate sales and control processes of hotel businesses. With the continuous growth of the market, the increase in online sales channels cause information pollution both for the end users and hotel businesses and give rise to ethical problems.CMS system which is discussed in this study is one of the new systems which is developed in order to overcome such mentioned problems.Revealing the importance of CMS which facilitates the management of online sales channels of hotels can boost sales and profit rates.The benefits of using CMS which collects all the sales channels of a hotel in various meta-search sites on a single page and act as a control panel for their reservation and sales processes can be listed as below:

- With instant updates of the hotel's information on various meta-search sites, it provides reliable and up-to-date information.

- By inputting the content and visuals of the hotel simultaneously to all the sales channels at once, it reduces time and increases the efficiency of the hotel businesses.

- Since CMS managers follow the destination/region sales and can inform such information to hotels through the system, it enables the hotel to compete in terms of pricing and setting out competency strategies. 
- CMS provides an advantage in terms of cost of the sales.Hotel enterprises can work with lower commission rates than the amounts paid to the local travel agents and/or during the sales made at reception desk.

- CMS also positively affects the sales performance of the hotels.Hotels can change their prices and sales strategies in different periods by using CMS system and increase their profitability.

- The extent of CMS contacts web affects the recognition and prestige of the hotel positively.

- It increases the visibility in meta-search in the destinations where there are a lot of hotels.By this way, in terms of positioning themselves, they may create an image of being in the top lists in the minds of its guests as it appears on the top ranks in meta-search.

- CMS increases room sales revenues.It allows hotelsto change the price of last remaining rooms through the system and by this way they can increase their profit.

- By using CMS, the number of staff in marketing and sales departments can be decreased and thus enhance the efficiency by working with less personnel.

This study which aims to bring a new perspective on tourism intended online sales,inspects the structure of the system.For this reason, finding about the topic are limited relatively.In order to better understand the influence of CMS on sales performance and its contribution to time-cost savings, it is necessary to do empirical studies about this issue.Such studies can make important contributions to the field by comparingoccupancy and profit rates periodically, by comparing online sales performances and profitability of hotels using the system with the ones which does not, and byassigning the requirements of the infrastructure for CMS system.

\section{REFERENCES}

1. Aksu, A. and Tarcan, E. (2002). The Internet and Five-star Hotels: A Case Study from the Antalya Region in Turkey, International Journal of Contemporary Hospitality Management, 14(2), 94-97.

2. Bilgihan, A., Barreda, A., Okumuş, F. and Nusair, K. (2016). Consumer Perception of Knowledge-sharing in Travel Related Online Social Networks, Tourism Management, 52, 287-296.

3. GoogleTravelStudy, 2014.Erişim Tarihi: 20 Ocak 2015, https://storage.googleapis.com/think/docs/2014-travelers-road-todecision_research_studies.pdf.

4. Heung, V.C.S. (2003). Internet Usage by International Travellers: Reasons and Barriers, International Journal of Contemporary Hospitality Management, 15(7), 370378.

5. Kucukusta, D., Law, R., Besbes, A., and Legoherel, P. (2015). Re-Examining Perceived Usefulness and Ease of Use in Online Booking, The Case of Hong Kong 
Online Users, International Journal of Contemporary Hospitality Management, 27(2), 185-198.

6. Law, R., Chan, I, and Goh, C. (2007). Where to Find the Lowest Hotel Room Rates on the Internet? The Case of Hong Kong, International Journal of Contemporary Hospitality Management, 19(6), 495-506.

7. Murphy, H.C., Chen, M.M. and Cossutta, M. (2016). An Investigation of Multiple Devices and Information Sources Used in the Hotel Booking Process, Tourism Management, 52, 44-51.

8. Murphy, H.C., Dang, Y. and Chen, M.M. (2015). An Examination of the E-Bookers and E-Browsers in Emerging Markets: Online Browsing Behaviour in Independent Hotels in Hoi An. In L. Tissyadiah and A. Inversini (Eds), Information and Communication Technologies in Tourism 2015, Proceedings of the International Conference in Lugano, Switzerland.

9. Smartphone Users Worldwide, 2012-2018. Accessed on 20 August 2015, http://www.statista.com/statistics/330695/number-of-smartphone-users-worldwide/

10. World Internet Users and 2015 Population Stats. Accessed on 20 August 2015, http://www.internetworldstats.com/stats.htm.

11. Zafiropoulos, C., Vrana, V. and Paschaloudis, D. (2006). The Internet Practices of Hotel Companies: An Analysis from Greece, International Journal of Contemporary Hospitality Management, 18(2), 156-163. 